\title{
AVALIAÇÃO DE ALGORITMOS PARA CLASSIFICAÇÃO DE USO E COBERTURA DA TERRA NA PORÇÃO CENTRAL DO RIO GRANDE DO SUL A PARTIR DE IMAGENS DE ALTA E MÉDIA RESOLUÇÃO ESPACIAL
}

\author{
EVALUATION OF ALGORITHMS FOR LAND USE AND LAND COVER CLASSIFICATION IN THE CENTRAL PORTION OF \\ RIO GRANDE DO SUL STATE FROM HIGH AND MEDIUM SPATIAL RESOLUTION IMAGERY
}

\section{RESUMO}

Analisar algoritmos de classificação do uso e cobertura da terra bem como imagens provenientes de sensores a bordo de satélites com diferentes resoluções espaciais são essenciais para determinar os mais adequados para cada local. Assim, o presente estudo tem por objetivo avaliar a eficiência de algoritmos de classificação supervisionada, Máxima Verossimilhança (MaxVer) e Bhattacharyya, utilizando imagens de resolução espacial média (OLI/Landsat 8) e alta (REIS/RapidEye), em municípios localizados na porção central do estado do Rio Grande do Sul. Foram utilizadas para a classificação imagens do sensor OLI/Landsat 8 e REIS/RapidEye, com resolução espacial de 30 e $5 \mathrm{~m}$, respectivamente. A classificação de ambas as imagens foi realizada pelos algoritmos MaxVer e Bhattacharyya com a definição de seis classes de uso e cobertura da terra, sendo estas Floresta nativa, Floresta plantada, Solo exposto, Agricultura, Campo e Água. Para avaliar a eficiência da classificação foram utilizados 120 pontos distribuídos de forma aleatória estratificada em cada município, sendo 20 pontos em cada classe de uso e cobertura da terra. A qualidade da classificação foi analisada pelos índices Kappa e exatidão global, ainda, calculou-se o erro de omissão e comissão. De acordo com os resultados obtidos o índice kappa foi maior para as classificações utilizando as imagens do sensor REIS/RapidEye para ambos os algoritmos, totalizando $85,33 \%$ (MaxVer) e $83,67 \%$ (Bhattacharyya). Neste contexto, foi possível concluir que as imagens REIS/RapidEye e o algoritmo MaxVer destacaram-se obtendo os melhores resultados, sendo estes mais adequados para a área de estudo.

Palavras-chave: Landsat 8. RapidEye. MaxVer. Bhattacharyya. Kappa.

\begin{abstract}
Analyzing classification algorithms of land use and land cover as well as images from sensors on satellites with different spatial resolutions are essential to determine the most suitable for each location. The objective of this study was to evaluate the efficiency of supervised classification algorithms, Maximum Likelihood (MLE) and Bhattacharyya, using medium spatial resolution (OLI/Landsat 8) and high (REIS/RapidEye) images in localized municipalities in the central of Rio Grande do Sul state. For this were used OLI/Landsat 8 and REIS/RapidEye sensor images with spatial resolution of 30 and $5 \mathrm{~m}$, respectively. The classification of both images was performed by the MLE and Bhattacharyya algorithms with the definition of six classes of land use and land cover, these being Native Forest, Planted Forest, Exposed Soil, Agriculture, Field and Water. To evaluate the efficiency of the classification were used 120 points distributed randomly stratified in each municipality, 20 points in each class of land use and land cover. The quality of the classification was analyzed by Kappa and global accuracy indices, and the error of omission and commission was calculated. According to the results, the kappa index was higher for the classifications using the REIS/RapidEye sensor images for both algorithms, totaling $85.33 \%$ (MLE) and $83.67 \%$ (Bhattacharyya). In this context, it was possible to conclude that the REIS/RapidEye images and the MLE algorithm stand out for the best results, which are more adequate for the study area.
\end{abstract}

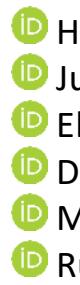
Helena Silva Oliveira ${ }^{a}$ Juliana Marchesan ${ }^{a}$ Elisiane Alba ${ }^{b}$ Dionatas Henrique Honnef ${ }^{a}$ Matheus Frigo Wolfer ${ }^{\text {a }}$ Rudiney Soares Pereira ${ }^{a}$

a Universidade Federal de Santa Maria (UFSM), Santa Maria, RS, Brasil

${ }^{\text {b }}$ Universidade Federal Rural de Pernambuco (UFRPE), Serra Talhada, PE, Brasil

DOI: $10.12957 /$ geouerj.2020.43259

Correpondência: marchesan.ju@gmail.com

Recebido em: 10 jun. 2019 Revisado em: 6 out. 2020 Aceito em: 11 nov. 2020

Keywords: Landsat 8. RapidEye. MLE. Bhattacharyya. Kappa. 


\section{INTRODUÇÃO}

As mudanças na paisagem têm ocorrido em uma velocidade exponencial devido ao processo de antropização. Com isso, nos últimos anos, o monitoramento das mudanças nos usos e cobertura da terra tornouse importante para a compreensão dos processos e dinâmicas que atuam nos diferentes espaços, possibilitando o planejamento territorial (SEABRA et al., 2015).

Assim, mapear e monitorar o uso e cobertura da terra vem se tornando uma forma de analisar as alterações ocorridas durante décadas. Para tal, tem-se utilizado técnicas de sensoriamento remoto, pois proporcionam agilidade no processamento dos dados (VAEZA et al., 2010). Uma das formas mais recorrentes de analisar as mudanças nos usos e cobertura da terra são por meio de imagens de sensores remotos a bordo de satélites (ANDRADE et al., 2019).

Antunes e Siqueira (2013) salientaram que imagens de sensores vêm apresentando uma vasta gama de avanços em diversas áreas de estudo, como na preservação de áreas permanentes, monitoramento sobre áreas agrícolas e florestais, entre outros. Nos dias atuais, há diversos sistemas sensores para os mais variados fins. Para o monitoramento do uso e cobertura da terra utiliza-se em grande escala os sensores OLI (Operacional Land Imager), a bordo do satélite Landsat 8, e o REIS (RapidEye Earth Imaging System), satélite RapidEye (SCHUSTER et al., 2012; LIU et al., 2014).

O satélite Landsat 8, por meio do sensor OLI, vêm obtendo imagens da superfície terrestre desde 2013 e apresenta inovações em relação aos satélites anteriores da série, sendo uma delas a resolução radiométrica a qual passou de oito para 16 bits permitindo maior diferenciação dos alvos (KALAF et al., 2013). Este satélite é amplamente utilizado para classificação do uso e cobertura da terra e em pesquisas de mudanças climáticas (LIU et al., 2014).

A constelação de satélites RapidEye, por sua vez, carrega abordo o sensor REIS (RapidEye Earth Imaging System), o qual dispõe de imagens de alta resolução espacial (cinco metros) e ainda a banda RedEdge que tem sido utilizada com a finalidade de aperfeiçoar o resultado da classificação do uso e cobertura da terra (SCHUSTER et al., 2012). Auxiliando assim, no planejamento territorial (MOURA et al., 2013) uma vez que permite discriminar diferentes coberturas vegetais.

Para monitorar a superfície terrestre são utilizados classificadores de modo a obter a quantificação dos usos e cobertura da terra. Assim, as técnicas de classificação têm por objetivo gerar mapas temáticos por meio da extração de informações das imagens (MENESES e SANO, 2012). A classificação se divide em dois processos, supervisionado e não-supervisionado. A classificação supervisionada requer que o usuário possua conhecimento prévio da área de estudo, enquanto que na não-supervisionada os pixels são designados para as classes existentes sem a interferência do usuário (NOVO, 2010). Em função disso, a classificação supervisionada gera maior precisão 
nos resultados, uma vez que é necessário o conhecimento prévio da área em estudo e dos usos e cobertura da terra que se deseja classificar (OLIVEIRA e MATTOS, 2014).

Neste contexto, analisar algoritmos de classificação do uso e cobertura da terra bem como imagens provenientes de sensores a bordo de satélites com diferentes resoluções espaciais são essenciais para determinar os mais adequados para cada local. Diante do exposto, o presente estudo teve por objetivo avaliar a eficiência de algoritmos de classificação supervisionada, Máxima Verossimilhança (MaxVer) e Bhattacharyya, utilizando imagens de resolução espacial média (OLI/Landsat 8) e alta (REIS/RapidEye), em municípios localizados na porção central do estado do Rio Grande do Sul.

\section{MATERIAIS E MÉTODOS}

Localização e caracterização da área de estudo

A área de estudo compreende três municípios da porção central do estado do Rio Grande do Sul, conforme a Figura 1. O município de Faxinal do Soturno apresenta extensão territorial de $169,5 \mathrm{~km}^{2}$, Ivorá abrange 122,9 km² e Sobradinho 128,0 km² (IBGE, 2016a).

Figura 1. Localização dos municípios de Ivorá, Faxinal do Soturno e Sobradinho no estado do Rio Grande do Sul
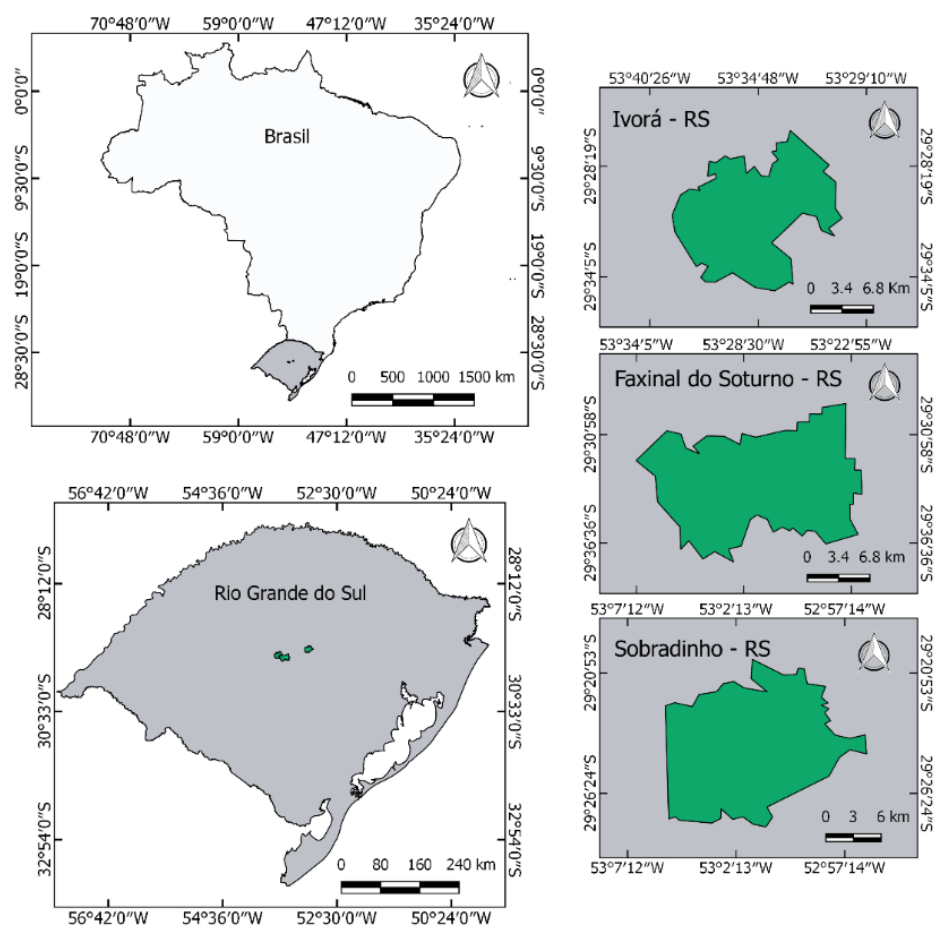

Sistema de Coordenadas

LatLong
Datum WGS84

Base Cartográfica:

Malha do Brasil, do Rio Grande do Sul e dos Municípios disponibilizados pelo IBGE (2015) na escala 1:250.000

Fonte: Elaborado pelos autores (2019). 
O clima local, conforme a classificação de Köppen, corresponde ao Subtropical Úmido (Cfa), com temperaturas médias anuais variando entre $16 \circ \mathrm{C}$ e $20^{\circ} \mathrm{C}$, as precipitações são bem distribuídas durante o ano, com variações entre 1.600 e 1.900 mm (ALVARES et al., 2014). A área de estudo caracteriza-se pela produção agrícola e pecuária. Sendo Faxinal do Soturno o município que apresenta maior área de arroz irrigado, em comparação aos demais, com 2.000 hectares plantados com o cultivo, seguido das culturas de soja, fumo e milho. O município de Ivorá, por sua vez, produz principalmente soja (3.000 ha), seguido do milho e fumo, enquanto que o município de Sobradinho tem por produção com maior geração de lucro local o cultivo de tabaco (1.850 ha), e em menor proporção soja e milho (IBGE, 2016b).

\section{Mapeamento do uso e cobertura da terra}

A criação do banco de dados espacial e o processamento das imagens foram realizados no software SPRING - Sistema de Processamento de Informações Georreferenciadas (CÂMARA et al., 1996), versão 5.2.7, no qual, criouse posteriormente um projeto com a projeção Equiretangular Cilíndrica Normal, Datum WGS84, Sistema de

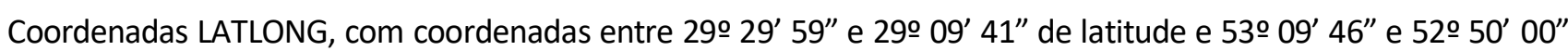
de longitude.

Utilizou-se uma imagem orbital do sensor OLI, satélite Landsat 8, capturada no mês de fevereiro de2016, com resolução espacial de 30 metros e radiométrica de 16 bits, adquirida gratuitamente pela USGS (United States Geological Survey). Ainda foram utilizadas duas imagens do sensor REIS, satélite RapidEye, obtidas no mês de fevereiro de 2016, com resolução espacial de 5 metros, 12 bits de resolução radiométrica, adquiridas por meio de um projeto entre a Universidade Federal de Santa Maria e o Sindicato Interestadual da Indústria do Tabaco (SINDITABACO).

Com a criação do banco de dados, iniciou-se o processo de edição das imagens, aplicando contraste linear e posterior classificação. O contraste linear foi composto pela combinação RGB 654 (Bandas 6, 5 e 4, correspondentes ao infravermelho médio, infravermelho próximo e ao vermelho, respectivamente), para as imagens OLI/Landsat8, e RGB 453 (Bandas 4, 5 e 3, referentes à RedEdge, infravermelho próximo e ao vermelho, respectivamente), para as imagens REIS/RapidEye, uma vez que foram as melhores combinações para diferenciação dos alvos em estudo.

As imagens de ambos os sensores foram submetidas ao processo de classificação utilizando os algoritmos classificadores Bhattacharyya e Máxima Verossimilhança (MaxVer), de modo a compará-los, utilizando o limiar de aceitação de 99\%. O algoritmo Bhattacharyya é um classificador supervisionado, baseado na determinação da separabilidade estatística entre duas classes, em que compara regiões da imagem, distintamente, através da distância Bhattacharyya (JENSEN, 2009), medindo a distância média entre as distribuições de probabilidade das 
classes (BRITES et al., 2012). Ainda, segundo os autores, este classificador requer a seleção de áreas de treinamento, podendo ser regiões adquiridas pela segmentação ou polígonos representativos das regiões a serem classificadas.

O classificador MaxVer, por sua vez, associa classes considerando pixels individuais da imagem, com isso, o algoritmo calcula a probabilidade de um pixel pertencer a uma classe ou não (LEITE e ROSA, 2012). Assim, cada pixel é destinado à classe com maior probabilidade, ou seja, máxima verossimilhança, dessa forma, para um pixel um conjunto de probabilidades são computadas e retornam as possibilidades do pixel pertencer a cada classe existente (MENESES e ROSA, 2012). Neste âmbito, o algoritmo realiza a classificação pixel a pixel (INPE, 2006a), diferentemente do Bhattacharyya que utiliza regiões para classificação.

Ambos os classificadores descritos se enquadram na classificação supervisionada, na qual o algoritmo é treinado para diferenciar as classes. Assim o procedimento é controlado pelo usuário, em que este escolhe as regiões (conjunto de pixels) representativas da classe, sendo estas utilizadas como amostras para o processo de classificação (MENESES e SANO, 2012). Dessa forma, na classificação supervisionada é necessário que o analista possua conhecimento prévio da área de estudo (NOVO, 2010).

O processo de segmentação, etapa que antecede a classificação, divide a imagem em regiões que representam um conjunto de pixels contíguos uniforme (INPE, 2006b), assim, foi necessária para o algoritmo Bhattacharyya, uma vez que este classifica a imagem conforme uma região delimitada previamente. Entre as técnicas utilizou-se a de crescimento de regiões, para a qual foi necessária a definição dos parâmetros de similaridade e área, sendo utilizado os valores de 10 e 100, respectivamente, pois foram os que melhor se adequaram a área de estudo.

Para as classificações foram definidas seis classes temáticas: Floresta nativa, Floresta plantada, Solo exposto, Agricultura, Campo e Água. A classe Floresta nativa compreendeu áreas compostas por fragmentos de vegetação arbórea; Floresta plantada compôs áreas com plantios de eucalipto e pinus; a classe Solo exposto abrangeu áreas em preparo de solo para a introdução de uma cultura ou pós colheita, assim como estradas; a Agricultura compreendeu os locais com cultivos agrícolas em diversos estágios; o Campo abrangeu áreas de vegetação rasteira nativa; e a classe Água foi representada por reservatórios e rios de modo geral. A área urbana dos municípios foi delimitada manualmente de modo a não interferirem no processo de classificação. Ainda, foi criada a classe denominada de áreas não identificadas para representar as regiões cobertas por nuvem.

\section{Análise da exatidão da classificação}

De modo a verificar a eficiência da classificação do uso e cobertura da terra para ambos os sensores (OLI e REIS) e classificadores (Bhattacharyya e MaxVer) foi gerada uma matriz de confusão, com a utilização de 120 pontos distribuídos de forma aleatória estratificada em cada município de análise, sendo 20 pontos em cada classe de uso 
e cobertura da terra, para cada classificador utilizado, conforme a metodologia proposta por Congalton (1991). A matriz de confusão compara cada classe por meio dos dados de referência (verdade terrestre) e os resultados da classificação (MENESES E SANO, 2012). Para tal, utilizou-se como referência imagens do Goolge Earth Pro ${ }^{T M}$ (GOOGLE INC., 2017) com datas coincidentes aos meses e anos das imagens em estudo.

Com a obtenção da matriz de confusão foi possível calcular o índice Kappa, proposto por Cohen (1960) conforme a Equação 1. Este índice é um dos parâmetros mais utilizados para verificar a exatidão da classificação de usos e cobertura a terra (MANGABEIRA et al., 2003), uma vez que considera todos os elementos da matriz de confusão (COHEN, 1960).

$$
k=\frac{N \sum_{i=1}^{r} X_{i j}-\sum_{i=1}^{r} X_{i+} X_{+i}}{N^{2}-\sum_{i=1}^{r} X_{i+} X_{+1}}
$$

Em que: $r=$ número de classes; $X_{i j}=$ número de elementos classificados corretamente; $X_{i+}=$ total de elementos classificados para uma categoria $i ; X_{+i}=$ total de elementos de referência amostrados para uma categoria $i ; \mathrm{N}=$ número total de amostras.

Para avaliar a qualidade da classificação, utilizando o resultado do índice Kappa, baseou-se na classificação proposta por Landis e Koch (1977), conforme a Tabela 1.

Tabela 1. Qualidade da classificação de acordo com as faixas do índice Kappa.

\begin{tabular}{cc}
\hline Faixas (\%) & Qualidade da classificação \\
\hline $0-\mid 10$ & Péssima \\
$10-\mid 20$ & Ruim \\
$20-\mid 40$ & Razoável \\
$40-\mid 60$ & Boa \\
$60-\mid 80$ & Muito Boa \\
$80-\mid 100$ & Excelente \\
\hline & Fonte: Landis e Koch (1977).
\end{tabular}

Ainda, calculou-se, utilizando a matriz de confusão, a exatidão global conforme a Equação 2. A mesma é obtida pela razão entre os elementos da diagonal principal e a totalidade dos pontos amostrados (CHUVIECCO, 1995).

$$
F m=\sum \frac{X_{i}}{N} \times 100
$$


Em que: $\mathrm{Fm}$ = exatidão global; $\mathrm{X}_{\mathrm{i}}=$ elementos na diagonal; $\mathrm{N}=$ total de elementos amostrados.

De modo a analisar a exatidão da classificação para cada classe de uso e cobertura da terra individualmente foi calculado o erro de omissão (Equação 3) e comissão (Equação 4). O primeiro indica o número de amostras que não foram classificadas de acordo com as classes de referência, enquanto que o segundo refere-se as amostras que foram inclusas em uma classe à qual não pertence na realidade (FRANCISCO e ALMEIDA, 2012).

$$
E_{0}=\frac{X_{i+}-X_{i i}}{X_{i+}}
$$

Em que: $E_{0}=$ erros de omissão; $X_{+i}=$ marginal da linha; $X_{i i}=$ diagonal daquela linha.

$$
E_{0}=\frac{X_{+i}-X_{i i}}{X_{+i}}
$$

Em que: $E_{c o}=$ erros de comissão; $X_{+i}=$ marginal da coluna; $X=$ diagonal daquela coluna.

Os erros de omissão e comissão foram obtidos em porcentagem, os quais foram denominados de risco do produtor e risco do usuário, respectivamente.

\section{Resultados e Discussão}

\section{Mapeamento dos usos e cobertura da terra}

A espacialização das classes temáticas dos usos e cobertura da terra para os municípios em estudo e para cada algoritmo classificador está exposta nas Figuras 2 e 3 as quais representam o resultado da classificação utilizando as imagens do sensor OLI/Landsat 8 e REIS/RapidEye, respectivamente. 
Figura 2. Mapeamento do uso e cobertura da terra por meio dos algoritmos MaxVer e Bhattacharyya utilizando imagem OLI/Landsat 8 nos municípios de Ivorá, Faxinal do Soturno e Sobradinho, Rio Grande do Sul

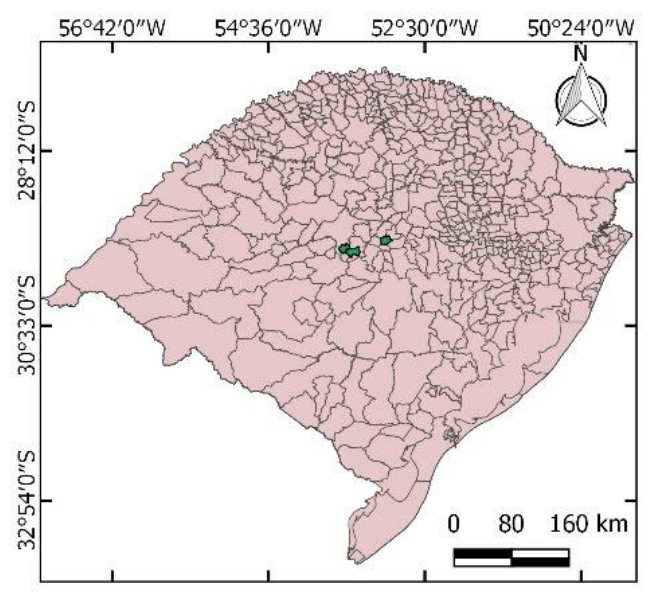

\section{USO E COBERTURA DA TERRA (OLI/LANDSAT 8)}

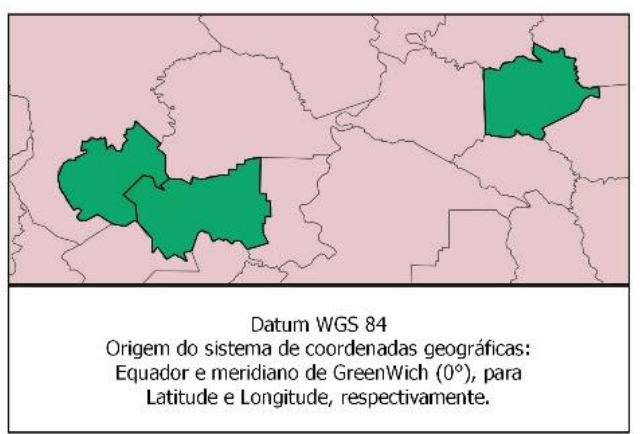

\section{Legenda}

Classes temáticas

Floresta Nativa

Floresta Plantada

Solo Exposto Agricultura

Campo

Água

Área não identificada

Área Urbana

Municipios em estudos

\section{MAXVER}
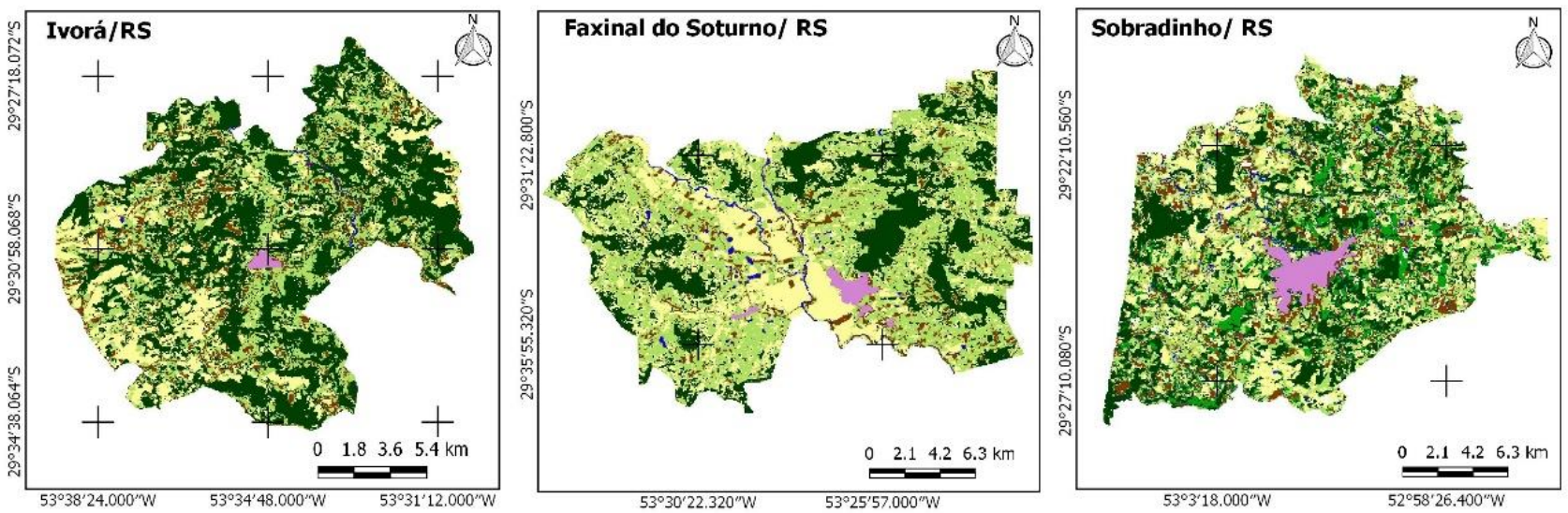

\section{BHATTACHARYYA}
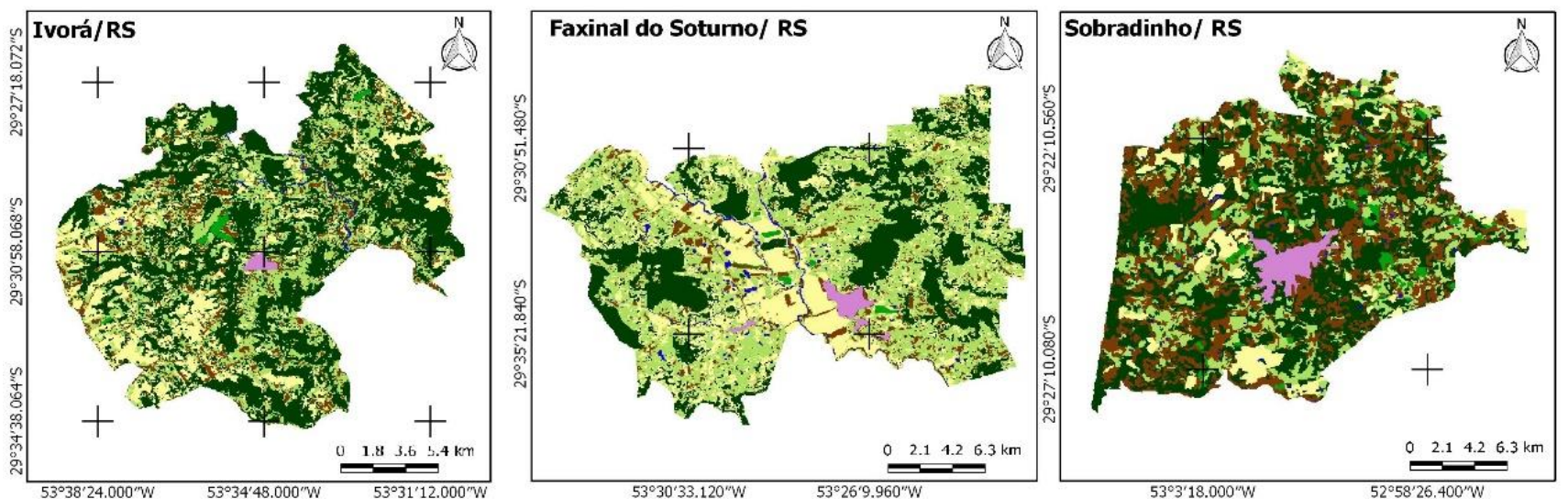

Fonte: Elaborado pelos autores (2019). 
Figura 3. Mapeamento do uso e cobertura da terra por meio dos algoritmos MaxVer e Bhattacharyya utilizando imagem REIS/RapidEye nos municípios de Ivorá, Faxinal do Soturno e Sobradinho, Rio Grande do Sul

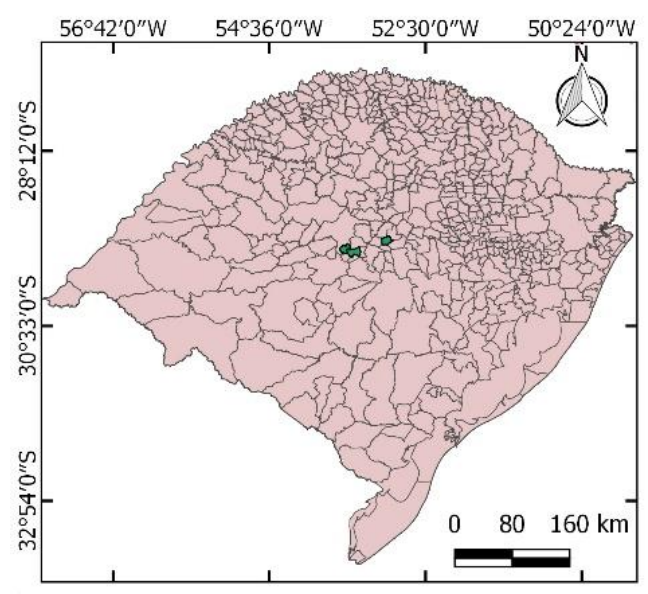

\section{USO E COBERTURA DA TERRA (REIS/RAPIDEYE)}

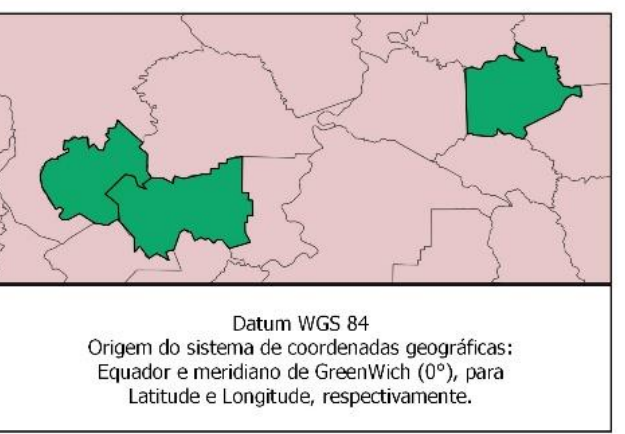

\section{Legenda}

Classes temáticas

Floresta Nativa

Floresta Plantada

Solo Exposto

$\checkmark$ Agricultura

Campo

Água

Área não identificada

Área Urbana

Municipios em estudos

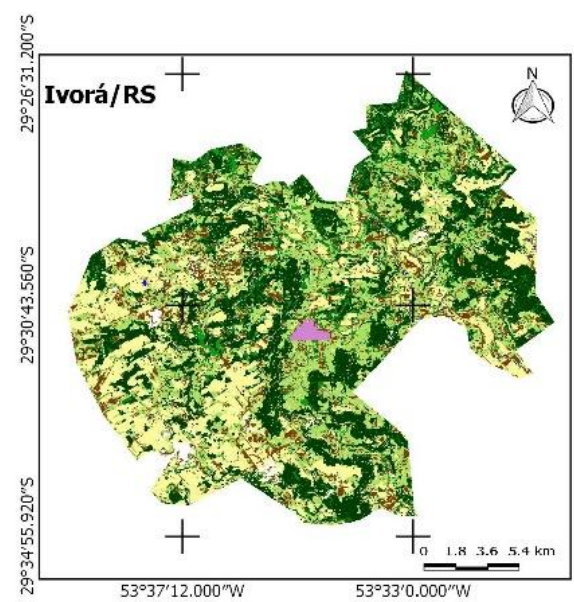

\section{MAXVER}
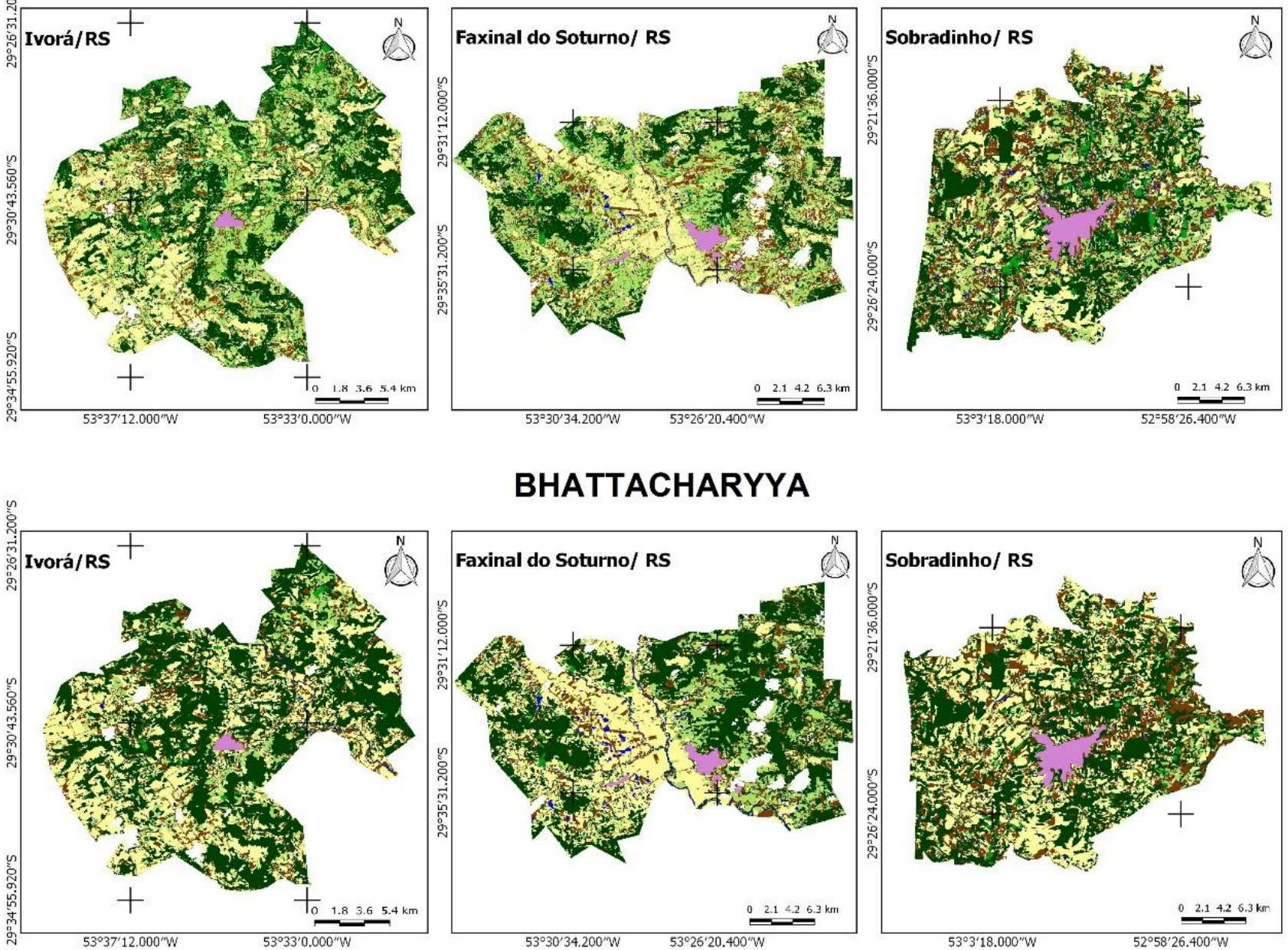

\section{BHATTACHARYYA}
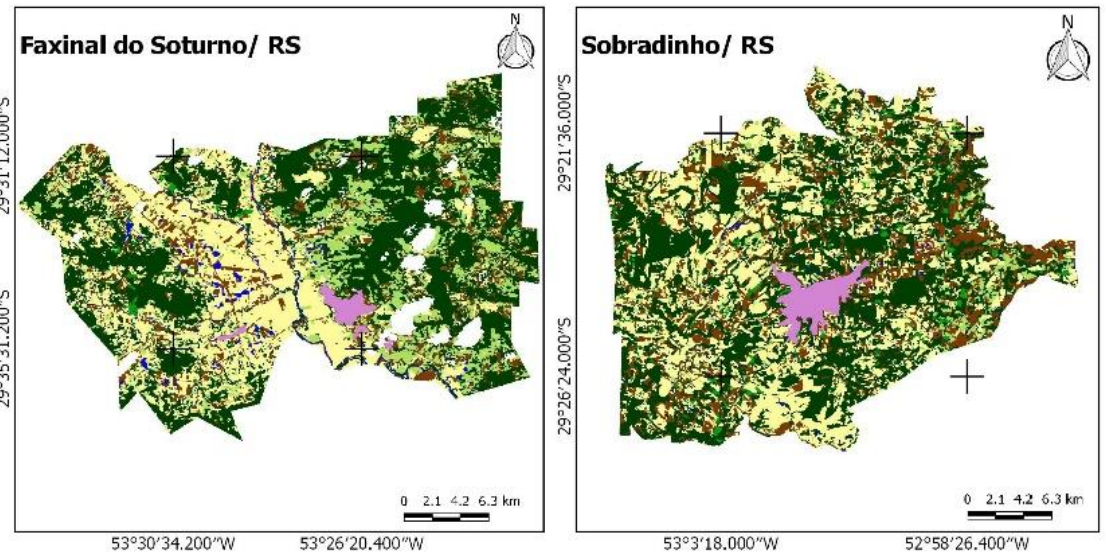

Fonte: Elaborado pelos autores (2019).

Nas Tabelas 2 e 3 tem-se as quantificações das classes temáticas para cada município, utilizando as imagens OLI/Landsat 8 e REIS/RapidEye, respectivamente. No município de Faxinal do Soturno foi constatada uma maior 
área ocupada por campo quando utilizadas imagens OLI/Landsat 8, totalizando 7.378,83 ha (37,65\% da área total de estudo) e 7.163,55 ha (36,46\%) para o classificador MaxVer e Bhattacharyya, respectivamente.

Tabela 2. Quantificação das classes temáticas por meio dos algoritmos MaxVer e Bhattacharyya utilizando imagem OLI/Landsat 8 nos municípios de Ivorá, Faxinal do Soturno e Sobradinho, Rio Grande do Sul, Brasil

\begin{tabular}{|c|c|c|c|c|}
\hline \multirow{3}{*}{ Classes Temáticas } & \multicolumn{4}{|c|}{ OLI/Landsat 8} \\
\hline & \multicolumn{2}{|l|}{ MaxVer } & \multicolumn{2}{|c|}{ Bhattacharyya } \\
\hline & Área (ha) & Área (\%) & Área (ha) & Área (\%) \\
\hline \multicolumn{5}{|c|}{ Faxinal do Soturno/RS } \\
\hline Floresta Nativa & $5.153,94$ & 26,30 & $5.639,22$ & 28,70 \\
\hline Floresta Plantada & 0,00 & 0,00 & 76,77 & 0,39 \\
\hline Solo Exposto & $1.254,06$ & 6,40 & $1.360,98$ & 6,93 \\
\hline Agricultura & $5.367,60$ & 27,39 & $4.950,09$ & 25,19 \\
\hline Campo & $7.378,83$ & 37,65 & $7.163,55$ & 36,46 \\
\hline Água & 207,27 & 1,06 & 219,06 & 1,11 \\
\hline Área não identificada & 0,00 & 0,00 & 0,00 & 0,00 \\
\hline Área Urbana & 237,88 & 1,27 & 237,88 & 1,27 \\
\hline \multicolumn{5}{|c|}{ Ivorá/RS } \\
\hline Floresta Nativa & $6.727,50$ & 47,30 & $6.638,67$ & 46,71 \\
\hline Floresta Plantada & 0,00 & 0,00 & 82,80 & 0,58 \\
\hline Solo Exposto & $1.244,88$ & 8,75 & $1.290,33$ & 9,08 \\
\hline Agricultura & $2.578,50$ & 18,13 & $2.553,75$ & 17,97 \\
\hline Campo & $3.577,50$ & 25,15 & $3.534,75$ & 24,87 \\
\hline Água & 35,01 & 0,25 & 49,05 & 0,35 \\
\hline Área não identificada & 0,00 & 0,00 & 0,00 & 0,00 \\
\hline Área Urbana & 61,57 & 0,44 & 61,57 & 0,44 \\
\hline \multicolumn{5}{|c|}{ Sobradinho/RS } \\
\hline Floresta Nativa & $3.719,61$ & 26,03 & $5.978,34$ & 40,43 \\
\hline Floresta Plantada & $1.692,63$ & 11,85 & 314,73 & 2,13 \\
\hline Solo Exposto & $1.779,30$ & 12,45 & $4.093,83$ & 27,68 \\
\hline Agricultura & $2.731,86$ & 19,12 & $1.134,99$ & 7,67 \\
\hline Campo & $3.653,91$ & 25,57 & $2.793,42$ & 18,89 \\
\hline Água & 287,91 & 2,02 & 58,23 & 0,39 \\
\hline Área não identificada & 0,00 & 0,00 & 0,00 & 0,00 \\
\hline Área Urbana & 414,81 & 2,97 & 414,81 & 2,97 \\
\hline
\end{tabular}

Fonte: Elaborado pelos autores (2019).

Com o uso da imagem OLI/Landsat 8 verificou-se diferenças significativas na quantificação das áreas no município de Sobradinho ao comparar os dois métodos de classificação utilizados. Nesse caso específico, essas 
diferenças são decorrentes das características do município, o qual engloba pequenas propriedades com usos diversos e cobertura florestal fragmentada, formando mosaicos. Esses fatores, juntamente com o tamanho do pixel da imagem (30 metros), acarretaram numa maior confusão na diferenciação das classes de uso nessa área de estudo.

Tabela 3. Quantificação das classes temáticas por meio dos algoritmos MaxVer e Bhattacharyya utilizando imagem OLI/Landsat 8 nos municípios de Ivorá, Faxinal do Soturno e Sobradinho, Rio Grande do Sul, Brasil

\begin{tabular}{|c|c|c|c|c|}
\hline \multirow{3}{*}{ Classes Temáticas } & \multicolumn{4}{|c|}{ REIS/RapidEye } \\
\hline & \multicolumn{2}{|c|}{ MaxVer } & \multicolumn{2}{|c|}{ Bhattacharyya } \\
\hline & Área (ha) & Área (\%) & Área (ha) & Área (\%) \\
\hline \multicolumn{5}{|c|}{ Faxinal do Soturno/RS } \\
\hline Floresta Nativa & $5.033,16$ & 26,71 & $7.798,89$ & 41,58 \\
\hline Floresta Plantada & 921,96 & 4,89 & 173,81 & 0,93 \\
\hline Solo Exposto & $2.835,32$ & 15,05 & $2.175,60$ & 11,60 \\
\hline Agricultura & $4.513,52$ & 23,95 & $5.450,50$ & 29,06 \\
\hline Campo & $5.137,92$ & 27,27 & $2.621,76$ & 13,98 \\
\hline Água & 163,83 & 0,87 & 298,26 & 1,59 \\
\hline Área não identificada & 755,99 & 4,00 & 890,85 & 4,75 \\
\hline Área Urbana & 237,88 & 1,27 & 237,88 & 1,27 \\
\hline \multicolumn{5}{|c|}{ Ivorá/RS } \\
\hline Floresta Nativa & $4.582,36$ & 32,23 & $6.643,84$ & 46,75 \\
\hline Floresta Plantada & 973,29 & 6,85 & 130,57 & 0,92 \\
\hline Solo Exposto & $1.426,18$ & 10,03 & $1.308,31$ & 9,21 \\
\hline Agricultura & $3.620,10$ & 25,47 & $4.775,17$ & 33,60 \\
\hline Campo & $3.317,25$ & 23,34 & $1.007,39$ & 7,09 \\
\hline Água & 22,66 & 0,16 & 76,07 & 0,53 \\
\hline Área não identificada & 211,55 & 1,49 & 208,00 & 1,46 \\
\hline Área Urbana & 61,57 & 0,43 & 61,57 & 0,43 \\
\hline \multicolumn{5}{|c|}{ Sobradinho/RS } \\
\hline Floresta Nativa & $4.820,49$ & 33,76 & $6.130,33$ & 40,17 \\
\hline Floresta Plantada & 571,41 & 4,00 & 273,70 & 1,79 \\
\hline Solo Exposto & $2.909,16$ & 20,37 & $2.683,44$ & 17,58 \\
\hline Agricultura & $2.145,42$ & 15,02 & $4.795,81$ & 31,43 \\
\hline Campo & $3.023,37$ & 21,17 & 654,23 & 4,29 \\
\hline Água & 173,79 & 1,22 & 72,18 & 0,47 \\
\hline Área não identificada & 221,58 & 1,55 & 236,15 & 1,55 \\
\hline Área Urbana & 414,81 & 2,90 & 414,81 & 2,72 \\
\hline
\end{tabular}


Com a utilização das imagens REIS/RapidEye houve maior abrangência da classe campo 5.137,92 ha (27,27\%) e floresta nativa $7.798,89$ ha (41,58\%), quando empregado o classificador MaxVer e Bhattacharyya, respectivamente. As imagens REIS/RapidEye possuem alta resolução espacial, com pixel no valor de 5 metros, desse modo, conseguem representar a área imageada com grande detalhamento. Nesse sentido, esse estudo demonstrou que esses produtos geram dados mais precisos quando utilizado um classificador por pixel, como é o caso do classificador MaxVer.

A quantificação da área obtida pelo MaxVer ao usar imagens REIS/RapidEye apresentou maior similaridade com os dados demonstrados acima, evidenciando maiores confusões ao utilizar o classificador Bhattacharyya, uma vez que seu algoritmo utiliza a resposta espectral dos pixels vizinhos, formando regiões similares, enquanto o MaxVer utiliza apenas a resposta espectral do pixel, individualmente.

Nos municípios de Faxinal do Soturno e Ivorá não foram contabilizados pixels que representassem a classe de floresta plantada quando utilizado o classificador MaxVer e imagens OLI/Landsat 8, enquanto a maior expressividade desta classe foi encontrada nas imagens REIS/RapidEye. Este fato pode ter ocorrido por confusão espectral entre a floresta plantada e outros usos com padrões semelhantes, como a floresta nativa.

Analisando o município de Ivorá notou-se que a floresta nativa apresentou maior predominância na área tanto para as imagens OLI/Landsat 8 quanto para as imagens REIS/RapidEye, sendo o valor superior obtido pelo classificador MaxVer por meio das imagens OLI/Landsat 8, totalizando 6.727,50 ha, equivalente à 47,30\% da área de estudo. A segunda classe de maior abrangência foi o campo, para as imagens OLI/Landsat 8, e agricultura, para as imagens REIS/RapidEye. Na classe de floresta plantada observou-se o mesmo comportamento que no município de Faxinal do Soturno, onde as maiores áreas foram encontradas nas imagens REIS/RapidEye, enquanto que nas imagens OLI/Landsat 8 utilizando o algoritmo MaxVer não foram detectados pixels representativos da classe.

Para o município de Sobradinho a floresta nativa teve maior abrangência para ambas as imagens e classificadores de análise, com área mais expressiva quando utilizado o classificador Bhattacharyya e imagens REIS/RapidEye totalizando $6 \cdot 130,33$ ha (40,17\%). A classe campo foi a segunda de maior abrangência quando empregado o classificador MaxVer, enquanto que para o classificador Bhattacharyya foi a classe solo exposto e agricultura para as imagens OLI/Landsat 8 e REIS/RapidEye, respectivamente. Cabe destacar que a classe solo exposto está inserida na classe agricultura, uma vez que representa as áreas de agricultura que estão em pousio ou em preparo para o plantio.

Nos municípios em estudo notou-se áreas expressivas ocupadas por campo e agricultura, demonstrando que os resultados estão em consonância com as características do local. Onde, a economia é de base agrícola com predomínio dos cultivos de arroz irrigado em Faxinal do Soturno, soja em Ivorá, e tabaco em Sobradinho (IBGE, 
2016b), sendo ocupada por pequenas propriedades rurais, devido à topografia que impede a implementação de lavouras extensivas (FARIAS, 2010).

Marchesan et al. (2018) analisando local próximo à área de estudo verificou o predomínio de áreas não florestais, abrangendo outros usos, como campos nativos, pastagens e agricultura, corroborando com o obtido no presente trabalho, em que nos municípios de análise a floresta nativa não chegou a abranger $50 \%$ da área. Contudo, Tramontina et al. (2015) analisando a dinâmica dos usos e cobertura da terra, por meio de imagens do sensor REIS/RapidEye, concluíram que as florestas nativas vêm aumentando na área, devido à regeneração florestal em áreas ocupadas anteriormente por agricultura e campo.

Quando utilizado o classificador MaxVer, notou-se, visualmente, que ocorreu maior heterogeneidade na classificação final (Figuras 2 e 3), especialmente para os usos e cobertura da terra que estavam dispostos em pequenas áreas, ou seja, haviam poucos pixels contíguos representativos da mesma classe, como foi o caso da classe campo, agricultura e solo exposto para os três municípios de estudo. Isto ocorreu devido o mesmo realizar o processo de classificação pixel a pixel, ao invés de englobar regiões.

Além disso, maior heterogeneidade foi observada nas classificações provenientes das imagens do sensor REIS/RapidEye quando comparada ao OLI/Landsat 8. Fato este relacionado, principalmente, à maior resolução espacial do sensor (cinco metros) que permite maior grau de detalhamento da paisagem, além de proporcionar maior diferenciação dos alvos devido à menor mistura espectral dos pixels situados na proximidade. No mesmo âmbito, Naesset et al. (2016), destacou que o sensor REIS/RapidEye é capaz de captar a heterogeneidade espacial dos usos e cobertura da terra, permitindo detectar pequenas áreas de floresta, campo, agricultura, entre outros.

\section{Análise da exatidão da classificação}

Os resultados obtidos pelo índice kappa indicaram concordância entre as imagens de referência e as classificações, conforme demonstram as Tabelas 4 e 5.

Tabela 4. Matriz de confusão da classificação utilizando imagem OLI/Landsat 8 e os classificadores MaxVer e Bhattacharyya

\begin{tabular}{|c|c|c|c|c|c|c|c|c|c|c|}
\hline \multicolumn{11}{|c|}{ Imagem OLI/Landsat 8 - Classificador MaxVer } \\
\hline & FN & FP & AG & SE & CA & ÁG & $\begin{array}{l}\overline{\text { तु }} \\
\text { ○ }\end{array}$ & $\frac{\bar{\varrho}}{\stackrel{\mathrm{O}}{\mathrm{m}}}$ & 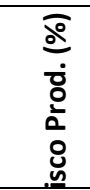 & 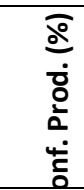 \\
\hline FN & 55 & 2 & 2 & 0 & 1 & 0 & 60 & 5 & 8,33 & 91,67 \\
\hline FP & 6 & 53 & 1 & 0 & 0 & 0 & 60 & 7 & 11,67 & 88,33 \\
\hline AG & 3 & 1 & 53 & 0 & 3 & 0 & 60 & 7 & 11,67 & 88,33 \\
\hline SE & 0 & 2 & 3 & 51 & 4 & 0 & 60 & 9 & 15,00 & 85,00 \\
\hline CA & 10 & 0 & 4 & 8 & 38 & 0 & 60 & 22 & 36,67 & 63,33 \\
\hline ÁG & 4 & 1 & 2 & 1 & 4 & 48 & 60 & 12 & 20,00 & 80,00 \\
\hline
\end{tabular}




\begin{tabular}{ccccccccccc}
\hline Total & 78 & 59 & 65 & 60 & 50 & 48 & $\mathbf{3 6 0}$ & - & - & - \\
\hline EC (\%) & 23 & 6 & 12 & 9 & 12 & 0,00 & - & - & - & - \\
\hline Risco Usuário (\%) & 29,49 & 10,17 & 18,46 & 15,00 & 24,00 & 0,00 & - & - & - & - \\
\hline Conf. Usuário (\%) & 79,51 & 89,83 & 81,54 & 85,00 & 76,00 & 100,00 & - & - & - & - \\
\hline Índice Kappa (\%) & $\mathbf{7 9 , 0 0}$ & - & - & - & - & - & - & - & - & - \\
\hline Exatidão global (\%) & $\mathbf{8 2 , 7 8}$ & - & - & - & - & - & - & - & - & - \\
\hline
\end{tabular}

Imagem OLI/Landsat 8-Classificador Bhattacharyya

\begin{tabular}{|c|c|c|c|c|c|c|c|c|c|c|}
\hline & FN & FP & AG & SE & CA & ÁG & $\begin{array}{l}\bar{\Gamma} \\
\stackrel{0}{\circ} \\
\end{array}$ & $\frac{\widehat{\circ}}{\circ}$ & 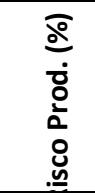 & 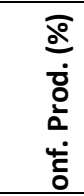 \\
\hline FN & 49 & 4 & 2 & 0 & 5 & 0 & 60 & 11 & 18,33 & 81,67 \\
\hline FP & 5 & 39 & 14 & 0 & 2 & 0 & 60 & 21 & 35,00 & 65,00 \\
\hline AG & 2 & 0 & 48 & 4 & 6 & 0 & 60 & 12 & 20,00 & 80,00 \\
\hline SE & 0 & 0 & 8 & 44 & 5 & 3 & 60 & 16 & 26,67 & 73,33 \\
\hline CA & 7 & 0 & 8 & 3 & 42 & 0 & 60 & 18 & 30,00 & 70,00 \\
\hline ÁG & 1 & 0 & 0 & 5 & 0 & 54 & 60 & 6 & 10,00 & 90,00 \\
\hline Total & 64 & 43 & 80 & 56 & 60 & 57 & 360 & - & - & - \\
\hline EC (\%) & 15 & 4 & 32 & 12 & 18 & 3 & - & - & - & - \\
\hline Risco Usuário (\%) & 23,44 & 9,30 & 40,00 & 21,43 & 30,00 & 5,26 & - & - & - & - \\
\hline Conf. Usuário (\%) & 76,56 & 90,70 & 60,00 & 78,57 & 70,00 & 94,74 & - & - & - & - \\
\hline Índice Kappa (\%) & 72,00 & - & - & - & - & - & - & - & - & - \\
\hline Exatidão global (\%) & 76,67 & - & - & - & - & - & - & - & - & - \\
\hline
\end{tabular}

Em que: FN: Floresta Nativa; FP: Floresta Plantada; AG: Agricultura; SE: Solo Exposto; CA: Campo; ÁG: Água; EO: Risco de Omissão; EC: Risco de Comissão; Risco Prod.: Risco do Produtor; Conf. Prod.: Confiança do Produtor; Conf. Usuário: Confiança do Usuário.

Fonte: Elaborado pelos autores (2019).

Tabela 5. Matriz de confusão da classificação utilizando imagem REIS/RapidEye e os classificadores MaxVer e Bhattacharyya Imagem OLI/Landsat 8 - Classificador MaxVer

\begin{tabular}{|c|c|c|c|c|c|c|c|c|c|c|}
\hline \multicolumn{11}{|c|}{ Imagem OLI/Landsat 8 - Classificador MaxVer } \\
\hline & $\mathbf{F N}$ & FP & AG & SE & CA & ÁG & $\begin{array}{l}\bar{\pi} \\
\text { 음 }\end{array}$ & $\begin{array}{l}\widehat{\varrho} \\
\text { o }\end{array}$ & $\begin{array}{l}\widehat{\varrho} \\
\dot{0} \\
\dot{0} \\
\overline{0} \\
\stackrel{0}{9}\end{array}$ & $\begin{array}{l}\widehat{亠} \\
\dot{0} \\
\dot{0} \\
\dot{0} \\
\dot{0} \\
\dot{0}\end{array}$ \\
\hline $\mathbf{F N}$ & 55 & 2 & 2 & 0 & 1 & 0 & 60 & 5 & 8,33 & 91,67 \\
\hline FP & 6 & 53 & 1 & 0 & 0 & 0 & 60 & 7 & 11,67 & 88,33 \\
\hline AG & 3 & 1 & 53 & 0 & 3 & 0 & 60 & 7 & 11,67 & 88,33 \\
\hline SE & 0 & 2 & 3 & 51 & 4 & 0 & 60 & 9 & 15,00 & 85,00 \\
\hline CA & 10 & 0 & 4 & 8 & 38 & 0 & 60 & 22 & 36,67 & 63,33 \\
\hline ÁG & 4 & 1 & 2 & 1 & 4 & 48 & 60 & 12 & 20,00 & 80,00 \\
\hline Total & 78 & 59 & 65 & 60 & 50 & 48 & 360 & - & - & - \\
\hline EC (\%) & 23 & 6 & 12 & 9 & 12 & 0,00 & - & - & - & - \\
\hline Risco Usuário (\%) & 29,49 & 10,17 & 18,46 & 15,00 & 24,00 & 0,00 & - & - & - & - \\
\hline Conf. Usuário (\%) & 79,51 & 89,83 & 81,54 & 85,00 & 76,00 & 100,00 & - & - & - & - \\
\hline Índice Kappa (\%) & 79,00 & - & - & - & - & - & - & - & - & - \\
\hline Exatidão global (\%) & 82,78 & - & - & - & - & - & - & - & - & - \\
\hline \multicolumn{11}{|c|}{ Imagem OLI/Landsat 8 - Classificador Bhattacharyya } \\
\hline & FN & FP & AG & SE & CA & ÁG & $\begin{array}{l}\bar{J} \\
\text { 。 }\end{array}$ & ঐ̊ & 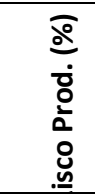 & 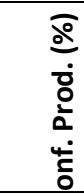 \\
\hline $\mathbf{F N}$ & 49 & 4 & 2 & 0 & 5 & 0 & 60 & 11 & 18,33 & 81,67 \\
\hline FP & 5 & 39 & 14 & 0 & 2 & 0 & 60 & 21 & 35,00 & 65,00 \\
\hline AG & 2 & 0 & 48 & 4 & 6 & 0 & 60 & 12 & 20,00 & 80,00 \\
\hline SE & 0 & 0 & 8 & 44 & 5 & 3 & 60 & 16 & 26,67 & 73,33 \\
\hline CA & 7 & 0 & 8 & 3 & 42 & 0 & 60 & 18 & 30,00 & 70,00 \\
\hline ÁG & 1 & 0 & 0 & 5 & 0 & 54 & 60 & 6 & 10,00 & 90,00 \\
\hline
\end{tabular}




\begin{tabular}{|c|c|c|c|c|c|c|c|c|c|c|}
\hline Total & 64 & 43 & 80 & 56 & 60 & 57 & 360 & - & - & - \\
\hline EC (\%) & 15 & 4 & 32 & 12 & 18 & 3 & - & - & - & - \\
\hline Risco Usuário (\%) & 23,44 & 9,30 & 40,00 & 21,43 & 30,00 & 5,26 & - & - & - & - \\
\hline Conf. Usuário (\%) & 76,56 & 90,70 & 60,00 & 78,57 & 70,00 & 94,74 & - & - & - & - \\
\hline Índice Kappa (\%) & 72,00 & - & - & - & - & - & - & - & - & - \\
\hline Exatidão global (\%) & 76,67 & - & - & - & - & - & - & - & - & - \\
\hline
\end{tabular}

Em que: FN: Floresta Nativa; FP: Floresta Plantada; AG: Agricultura; SE: Solo Exposto; CA: Campo; ÁG: Água; EO: Risco de Omissão; EC: Risco de Comissão; Risco Prod.: Risco do Produtor; Conf. Prod.: Confiança do Produtor; Conf. Usuário: Confiança do Usuário.

Fonte: Elaborado pelos autores (2019).

O índice kappa foi maior para as classificações utilizando as imagens do sensor REIS/RapidEye para ambos os algoritmos, totalizando 85,33\% e 83,67\%, para o MaxVer e Bhattacharyya, respectivamente. Estes índices apontaram uma qualidade da classificação "excelente" segundo a classificação de Landis e Koch (1997). Para as imagens OLI/Landsat 8 o Kappa foi de 79,00\% quando utilizado o algoritmo MaxVer e de 72,00\% para o Bhattacharyya, assim, a qualidade da classificação enquadrou-se como "muito boa" para ambos, de acordo com a Tabela 1.

Resultados semelhantes foram obtidos por Queiroz et al. (2017) ao analisarem a eficiência da classificação do uso e cobertura da terra, em área próxima à do presente estudo, por meio de imagens OLI/Landsat 8 e REIS/RapidEye e o algoritmo Bhattacharyya. Os autores obtiveram melhor valor Kappa para a classificação utilizando imagem do sensor REIS, o qual foi de $73 \%$, sendo de $59 \%$ o índice obtido para a classificação das imagens OLI. Do mesmo modo, Oliveira et al. (2015) obtiveram melhores resultados para classificação de fragmentos florestais quando utilizaram imagem REIS/RapidEye ao invés de TM/Landsat 5, por meio do algoritmo MaxVer.

Com relação aos classificadores utilizados no presente estudo destacou-se o MaxVer visto que se obteve os maiores valores Kappa para ambos os sensores de análise. Desse modo, o melhor resultado obtido para a classificação do uso e cobertura da terra na área de pesquisa foi utilizando as imagens REIS/RapidEye por meio do classificador MaxVer. Em concordância, Santos e Lima (2018) ao compararem algoritmos de classificação de uso e cobertura da terra, utilizando imagens OLI/Landsat 8, obtiveram melhores índices kappa para o algoritmo MaxVer.

Os índices de exatidão global seguiram a mesma tendência dos valores kappa, sendo o maior valor obtido para o classificador MaxVer utilizando imagens REIS/RapidEye, contudo, os valores encontrados foram maiores que o kappa. Brites (1996) retratou que o índice de exatidão global sempre resultará em valores maiores que o kappa, devido o mesmo não considerar os erros de comissão e omissão implícito na matriz de confusão. O índice kappa, por sua vez, calcula a concordância casual e inclui os elementos da diagonal principal, tornando a concordância superestimada e consequentemente reduzindo o valor do índice (BERNARDES et al., 2007). 
Para a classificação da imagem OLI/Landsat 8 utilizando o algoritmo MaxVer o menor erro de omissão foi observado na classe de Floresta Nativa, com valor de 8,33\% apontando que 5 amostras das 60 utilizadas não foram inclusas nesta classe. Contudo para a mesma classe foi encontrado o maior erro de comissão (29,49\%), indicando que houve inclusão errônea de 23 amostras de referência em outras categorias.

Analisando os resultados para a classificação da imagem OLI/Landsat 8 utilizando o algoritmo Bhattacharyya observou-se que o menor erro de omissão e comissão foi obtido para a classe água, totalizando 10,00\% e 5,26\%, respectivamente. O mesmo observou-se para a classificação da imagem REIS/RapidEye utilizando os algoritmos MaxVer e Bhattacharyya, com exceção do erro de comissão da imagem REIS por meio do classificador MaxVer. Os menores erros obtidos na classificação dos corpos hídricos devem-se ao fato desta classe apresentar como característica menor reflectância, se comparada as outras classes, o que torna a mesma diferente das demais, conforme citado por Caten et al. (2015), permitindo assim, obter menor confusão na classificação.

Na mesma tendência, Luz et al. (2015) avaliaram a exatidão da classificação híbrida por meio de imagens OLI/Landsat 8 e REIS/RapidEye e obtiveram resultados semelhantes aos encontrados no presente estudo, com erro de omissão e comissão menores para a classe referente aos corpos d'água, com valor de 3,72\% e 7,82\%, respectivamente. Ainda, Santos e Lima (2018) em estudo de classificação do uso e cobertura da terra utilizando imagens OLI/Landsat 8 por meio de diferentes classificadores encontraram resultados similares, no qual a classe água apresentou um dos menores erros de omissão e comissão perdendo apenas para a classe de solo exposto.

De modo geral, as imagens e os classificadores utilizados na presente pesquisa permitiram obter resultados satisfatórios quanto a classificação do uso e cobertura da terra. Porém, as imagens REIS/RapidEye proporcionaram obter uma classificação mais precisa, segundo os índices calculados, devido ao maior detalhamento das mesmas com relação às imagens OLI/Landsat 8. Com relação aos algoritmos testados notouse que o MaxVer foi mais adequado para a classificação do uso e cobertura da terra para a área de pesquisa em comparação ao Bhattacharyya.

Estes resultados estão diretamente ligados às características da área de estudo, a qual é ocupada por pequenas propriedades rurais, com cultivos agrícolas em pequenas áreas e criação de gado em campos nativos pouco extensos. Assim, estas características peculiares do local resultam em imagens orbitais heterogêneas, muitas vezes, com poucos pixels contíguos compondo uma determinada classe de uso ou até mesmo apenas um pixel representando a mesma, principalmente em sensores de menor resolução espacial.

Neste contexto, o algoritmo MaxVer permite classificar cada pixel de acordo com uma classe, ao contrário do Bhattacharyya que classifica por regiões. Desse modo, por meio da classificação pixel a pixel é 
possível maior diferenciação dos usos da terra nestas áreas, muitas vezes não reconhecidas em uma região no processo de segmentação (processo que antecede a classificação Bhattacharyya). Com isso, os resultados obtidos foram mais adequados para a área de estudo devido a estas características citadas, podendo não serem os mais apropriados para outras regiões.

\section{CONCLUSÕES}

Os melhores resultados, analisado pelo índice kappa, foram obtidos para as imagens REIS/RapidEye para ambos os algoritmos, totalizando $83,67 \%$ para o Bhattacharyya e $85,33 \%$ para o MaxVer. As imagens REIS/RapidEye possuem alta resolução espacial, com pixel no valor de 5 metros, as quais possibilitaram representar a área imageada com grande detalhamento. Além disso, o MaxVer destacou-se devido a permitir classificar pixel a pixel os usos e cobertura da terra, adequando-se a área de estudo, a qual é caracterizada por pequenas propriedades rurais e desse modo, as imagens apresentaram-se com pixels heterogêneos, com poucos pixels contíguos de uma mesma classe.

Neste contexto, foi possível inferir que para a área de estudo, situada na porção Central do Rio Grande do Sul, o método mais adequado de mapeamento do uso e cobertura da terra foi pelo algoritmo MaxVer, devido as características da área aliado ao método de classificação por pixel. Assim, o presente estudo poderá servir de base para trabalhos futuros de classificação do uso e cobertura da terra no local.

\section{REFERÊNCIAS}

ALVARES, Clayton Alcarde; STAPE, José Luiz; SENTELHAS, Paulo Cesar; DE MORAES, José LeonardoGonçalves; SPAROVEK, Gerd. Köppen's Climate Classification Map for Brazil.Meteorologische Zeitschrift, Stuttgart, v.22, n.6, p. 711-728, 2014.

ANDRADE, Leonardo Rosa; MOREIRA,João Paulo Papaleo Costa; SANTOS, Alex Mota. Análise Temporal do Uso e Cobertura da Terra na Bacia do Rio Boa Vista,Ouro Preto do Oeste-RO. Caderno de Geografia, v.29, n.56, p. 81-97, 2019.

ANTUNES, Mauro Antonio Homem; SIQUEIRA, Jéssica Caroline dos Santos. Características das imagens RapidEye para mapeamento e monitoramento e agrícola e ambiental. In: SIMPÓSIO BRASILEIRO DE SENSORIAMENTO REMOTO, 16, 2013, Foz do Iguaçu.

Sensoriamento remoto... Foz do Iguaçu: INPE, 2013. p. 0547-0554.

BERNARDES, Tiago; ALVES, Helena Maria Ramos; VIEIRA, Tatiana Grossi Chquiloff; ANDRADE, Hélcio. Avaliação da acurácia do mapeamento do uso da terra no complexo Serra Negra, Patrocínio, MG, por interpretação visual e classificação automática de imagens Landsat. In: SIMPÓSIO BRASILEIRO DE SENSORIAMENTO REMOTO, 13, 2007, Florianópolis. Anais... Florianópolis: INPE, 2007. p. 5587-5594.

BRITES, Ricardo Seixas. Verificação de exatidão em classificação de imagens digitais orbitais: efeito de diferentes estratégias de amostragem e avaliação de índices de exatidão. 1996. 101f. Tese (Doutorado em Ciência Florestal) - Universidade Federal de Viçosa, 1996.

BRITES, Ricardo Seixas; BIAS, Edilson de Souza; ROSA, Antonio Nuno de Castro Santa. Classificação por regiões. In:MENESES, Paulo Roberto; ALMEIDA, Tatide (Org.). Introdução ao processamento de imagensde sensoriamento remoto. Brasília: CNPQ, 2012. 219p. p. 209-220. 
CÂMARA, Gilberto; SOUZA, Ricardo Cartaxo Modesto; FREITAS, Ubirajara Moura; GARRIDO, Juan. SPRING: Integrating remote sensing and GIS by object-oriented data modelling. Computers \& Graphics, v.20, n.3, p. 395-403, 1996.

CATEN, Alexandre Ten; SAFANELLI, JOSÉ L.; RUIZ, LUIS F. C. Mapeamento multitemporal da cobertura de terra, por meio deárvore de decisão, na bacia hidrográfica do Rio Marombas-SC. Engenharia Agrícola, v.35, n.6, p. 1198-1209, 2015.

CHUVIECCO, Emílio. Fundamentos de Teledetección Espacial. 2 ed.España: Ediciones Rialp, 1995. 449p.

COHEN, Jacob. A coefficient of agreement for nominal scales. Educational and Psychological Measurement. Nova Yorque,v.20, n.1, p. 37-46, 1960.

CONGALTON, Russell G. A review of assessing the accuracy of classifications of remotely sensed data. Remote Sensing of Environment, v.37, n.1, p. 35-46, 1991.

FARIAS, Jorge Antonio. Atividade Florestal no Contexto da Fumicultura: Oportunidade de Desenvolvimento Regional, Diversificação, Geração de Emprego e Renda. 2010. 168f. Tese (Doutorado em Engenharia Florestal) - Universidade Federal de Santa Maria, 2010.

FRANCISCO, Cristiane Nunes; ALMEIDA, Cláudia Maria. Avaliação de desempenho de atributosestatísticos etexturais em uma classificaçãode cobertura da terra baseada em objeto. Boletim de Ciências Geodésicas, v.18, n.2, p. 302-326, 2012.

GOOGLE INC. Google Earth. 2017. Disponível em: <https://www.google.com/earth/>.

IBGE - Instituto Brasileiro de Geografia e Estatística. Cidades. 2016a. Disponível em: <https://cidades.ibge.gov.br/brasil/rs/>. Acesso em: 12 dezembro 2018.

IBGE - Instituto Brasileiro de Geografia e Estatística. Cidades: Produção temporária. 2016b. Disponível em: $<$ https://cidades.ibge.gov.br/brasil/rs/>. Acesso em: 15 dezembro 2018.

INPE - Instituto Nacional de Pesquisas Espaciais. Manuais. 2006a. Classificação de imagens. Disponível em: <http://www.dpi.inpe.br/spring/portugues/tutorial/classific.html>. Acesso em: 24 janeiro 2019.

INPE - Instituto Nacional de Pesquisas Espaciais. Segmentação de Imagens. 2006b. Disponível em: <http://www.dpi.inpe.br/spring/portugues/tutorial/segmentacao.html>. Acesso em: 24 janeiro 2019.

JENSEN, John. Introductory Digital Image Processing: a remoting sensing perspective. 3. ed. Califórnia: Prentice Hall, 2009.

KALAF, Raíssa; BRASILEIRO, Roberta; CARDOSO, Phillipe Valente; CRUZ, Carla Bernadete Madureira. Landsat 8: Avanços para mapeamento em mesoescala. In: CONGRESSO BRASILEIRO DE GEOPROCESSAMENTO, 4, 2013, Rio de Janeiro. Anais... Rio de Janeiro, 2013.

LANDIS, J. Richards; KOCH, Gary. G. The measurement of observer agreement for categorical data. Biometrics, v.33, n.1, 1977.

LEITE, Emerson Figueiredo; ROSA, Roberto. Análise do uso, ocupação e cobertura da terra da bacia hidrográfica do Rio Formiga, Tocantins. Revista Eletrônica de Geografia. v.4, n.12, p. 90-106, 2012.

LIU, Qingsheng; GUO, Yushan; LIU, Gaohuan; ZHAO, Jun. Classification of Landsat 8 OLI Image Using Support Vector Machine With Tasseled Cap Transformation. In: INTERNATIONAL CONFERENCE ON NATURAL COMPUTATION, 10, 2014, Xiamen. China: IEEE. 2014. p. 665-669.

LUZ, Naíssa Batista; OLIVEIRA, Yeda Maria Malheiros; ROSOT, Maria Augusta Doetzer; GARRASTAZÚ, Marilice Cordeiro; FRANCISCON, Luziane; MESQUITA JÚNIOR, Humberto Navarro de; FREITAS,Joberto Veloso de. Classificação híbrida de imagens Landsat-8 e RapidEye para o mapeamento do uso e cobertura da terra nas Unidades Amostrais de Paisagem do Inventário Florestal Nacional do Brasil. In: SIMPÓSIO BRASILEIRO DE SENSORIAMENTO REMOTO, 17, 2015, João Pessoa. Anais... João Pessoa: INPE, 2015. p. 72227230.

MANGABEIRA, João Alfredo de Carvalho; AZEVEDO, Emílio Carlos de; LAMPARELLI, Rubens Augusto Camargo. Avaliação do levantamento do uso das terras por imagens de satélite de alta e média resolução espacial. Comunicado técnico, 11, Campinas, SP, 2003, 15 p.

MARCHESAN, Juliana; PEREIRA, Rudiney Soares; ALBA, Elisiane; PEDRALI, Leticia Daiane. Spatial Analysis of Forest Fragmentation in the Atlantic ForestBioma Areas. Journal of Agricultural Science, v.10, n.12, p. 294-305. 2018. 
MENESES, Paulo Roberto; ROSA, Antonio Nuno de Castro Santa. Filtragem. In: MENESES, Paulo Roberto; ALMEIDA, Tati de (Org.). Introdução ao processamento de imagensde sensoriamento remoto. Brasília: CNPQ, 2012. 219p. p. 168-208.

MENESES, P. R.; SANO, Edson Eyji. Classificação pixel a pixel de imagens. In: MENESES, Paulo Roberto; ALMEIDA, Tatide(Org.). Introdução ao processamento de imagens de sensoriamento remoto. Brasília: CNPQ, 2012. 219p. p. 191-208.

MOURA,Ana Clara Mourão; SEPÚLVEDA,Cláudia Ladeia; RESENDE, Maisa Silveira; RIBEIRO, Suellen Roquete. Uso de imagens RapidEye como apoio à tomada de decisões no planejamento e gestão da paisagem do município de Bom Sucesso-MG. In: SIMPOSIO BRASILEIRO DE SENSORIAMENTO REMOTO, 16, 2013, Foz do Iguaçu. Anais... Foz do Iguaçu: INPE, 2013. p. 802-809.

NAESSET, Erik; ØRKA, Hans Ole; SOLBERG, Svein; BOLLANDSÅS,Ole Martin; HANSEN, Endre Hofstad; MAUYA, Ernest; ZAHABU, Eliakimu; MALIMBWI, Rogers; CHAMUYA, Nurdin; OLSSON, Håkan; GOBAKKEN, Terje. Mapping and estimating forest area and aboveground biomass in miombo woodlands in Tanzania using data from airborne laser scanning, TanDEM-X, RapidEye, and global forest maps: A comparison of estimated precision. Remote Sensing of Enviroment, v.175, p. 282-300, 2016.

NOVO, Evelyn. M. L. de Morais. Sensoriamento remoto: princípios e aplicações. 4. ed. SãoPaulo: Blucher, 2010. 387 p.

OLIVEIRA, Frederico F. G.; MATTOS, Juércio T. Análise ambiental de remanescentes do biomaMata Atlântica no litoral sul do Rio Grande do Norte, NE do Brasil. Espaço e Tempo(Online), São Paulo, v.18, n.1, p. 165-183, 2014.

OLIVEIRA, Felipe Pinho de; FERNANDES FILHO, Elpídio Inácio; SOUZA, Agostinho Lopes de; SOARES, Vicente Paulo. Mapeamento de Florestas Monodominadas por Myracrodruonurundeuva com Imagens TM - Landsat 5 e Rapideye. Floresta e Ambiente,v.22, n.3,p. 322-333, 2015.

QUEIROZ, Túlio Barroso, SOUSA, Rita dos Santos; BALDIN, Talita; BATISTA, Fábio de Jesus; MARCHESAN, Juliana; PEDRALI, Letícia Daiane; PEREIRA, Rudiney Soares. Avaliação do desempenho da classificação do uso e cobertura da terra a partir de imagens Landsat 8 e RapidEye na região central do Rio Grande do Sul.Geociências, v.36, n.3, p. 569 - 578, 2017.

SANTOS, Leovigildo Aparecido; LIMA, Paulo Eliardo Morais de. Comparação entre diferentes algoritmos de classificaçãosupervisionada no mapeamento temático de uma baciahidrográfica. Tree Dimensional, v.3, n.5, p.27-41, 2018.

SCHUSTER, Christian; FORSTER, Michael; KLEINSCHIMIT, Birgit. Testing the red edge channel forimproving land-use classifications based on high-resolution multi-spectral satellitedata. International Journal of Remote Sensing, v.33, n.17, p. 5583-5599, 2012.

SEABRA,Vinicius da Silva; XAVIER, Rafael Albuquerque; DAMASCENO,João; DORNELLAS, Patrícia da Conceição. Análise das mudanças de uso e cobertura da terra na bacia do rio Taperoá-PB entre os anos de 1990 e 2009. In: SIMPÓSIO BRASILEIRO DE SENSORIAMENTO REMOTO, 16. 2015, João Pessoa. Anais... São José dos Campos: INPE, 2015. p. 108-115.

TRAMONTINA, Juliana; PEDRALI, Letícia; ALBA, Elisiane; MELLO, Eliziane; SILVA, Emanuel Araújo, PEREIRA, Rudiney Soares. Modelagem Dinâmica do uso e cobertura da terra do município de Sobradinho-RS. In: SIMPOSIO BRASILEIRO DE SENSORIAMENTO REMOTO, 17, 2015, João Pessoa. Anais... João Pessoa: INPE, 2015. p. 4239-4246.

VAEZA, Rafael Franco; FILHO, Paulo Costa de O.; MAIA, Adelena Gonçalves; DISPERATI, Atílio Antonio. Uso e ocupação do solo em Bacia Hidrográfica urbana a partir de imagens orbitais de alta resolução. Floresta e Ambiente, v.17, n.1, p. 23-29, 2010. 